\title{
Electrochemical degradation of pharmaceutical compounds as Tetracycline in aqueous solution with BDD electrode
}

\author{
Carmen Brinzila ${ }^{1,2, a}$, Lurdes Ciríaco ${ }^{2}$, Maria Jose Pacheco ${ }^{2}$, Ana Lopes ${ }^{2}$, \\ Romeo Cristian Ciobanu ${ }^{1}$
}

\author{
${ }^{1}$ Faculty of Electrical Engineering, The "Gheorghe Asachi" Technical University of lasi, Bd. \\ Professor Dimitrie Mangeron, $n^{\circ} 21-23,700050$, lasi, Romania
}

${ }^{2}$ UMTP and Department of Chemistry, University of Beira Interior, 6200-001 Covilhã, Portugal

aemail, carmenbrinzila@gmail.com (corresponding author)

\section{Keywords: Antibiotics, Boron Doped Diamond, Electrochemical degradation.}

\begin{abstract}
Antibiotics named tetracycline (TC) are the most popular group of pharmaceutical compounds used in therapeutic purpose in human and veterinary medicine and in aquaculture, due to their characteristics as broad spectrum antibiotic. The tetracyclines are a group of natural and semisynthetic products that are bacteriostatic agents with activity against a wide variety of organisms, but of limited use today because of acquired resistance. Even at low concentrations, tetracycline and its metabolites may have a negative influence on the environment. Tetracycline is weakly metabolized or absorbed into the body, some of the ingested antibiotic being eliminated through urine and feces directly into the environment as most of the primarily unchanged form or secondary compounds. Nowadays tetracycline residues can be detected in surface water that was discharged from municipal wastewater treatment plants and agricultural drained. In this study, the degradation of tetracycline and the influence of experimental parameters (initial $\mathrm{pH}$, initial concentration, different flow velocity $(\mathrm{mL} / \mathrm{s})$, solution temperature $\left({ }^{\circ} \mathrm{C}\right)$, current intensity $\left.(\mathrm{mA})\right)$ on electrochemical degradation with BDD electrode were evaluated. The following parameters were analyzed for the samples collected during the electrochemical assays in electrochemical cell with stirrier and BDD/stainless steel electrodes: Chemical oxygen demand (COD), total organic carbon, nitrogen (total Kjeldhal, organic and inorganic), HPLC and UV-Visible absorption spectrophotometry.
\end{abstract}

\section{Introduction}

Due to the global consumption of antibiotics (100000-200000 tons per year), in recent years, an increasing concern focuses on the presence of pharmaceuticals in the aquatic environment. Among a variety of pharmaceuticals, antibiotics are most frequently detected in the environment that are difficult to be removed through conventional biological treatment methods.

Pharmaceuticals named antibiotics are potent bioactive chemicals that can be grouped by either their chemical structure or mechanism of action, and can be divided into different subgroups such as $\beta$-lactams, quinolones, tetracyclines, macrolides, sulphonamides and others [1].

Tetracyclines (TC) are a group of natural and semisynthetic products characterized by four rings structure with a carboxylamide functional group and as side chains, several other ionizable functional groups which are responsible for their charge (Fig. 1).

TC are amphoteric molecules having those ionizable groups that give a molecule its pKa, giving rise to negative, cationic, or zwitterion charged species [2].

TC are used as bacteriostatic agents, inhibit the synthesis of bacterial proteins, with activity against a wide variety of organisms in human and veterinary medicine as well in aquaculture for preventing or treating microbial infections [1,3]. Due to their antimicrobial proprieties, oxytetracyclines are used in controlling bacterial diseases of tree fruits in USA. Because of some characteristics such as: active on and inside the plant, tolerate oxidation, UV irradiation, rainfall and high temperature, TC are preferred in fruit growing industry becoming the main factor of environment problems. 
Tetracycline group of antibiotics is the second most widely used antimicrobial in both production and usage, worldwide, with applications in human therapy and in the livestock industry, like aquaculture and veterinary medicine [4]. TCs are weakly metabolized or absorbed into the human or animal body, some of the ingested antibiotic being eliminated through urine and feces directly into the environment as most of the primarily unchanged form or secondary compounds.

The extensively use of TC has lead to a negative influence on the environment, even at low concentrations, tetracycline and its metabolites (4-epi-tetracycline) are later released into aquatic environment usually after the physical/chemical and biological process in wastewater treatment plants [5].

Nowadays tetracycline residues can be detected in surface water that was discharged from municipal wastewater treatment plants and agricultural drained. The presence of residual pharmaceuticals in the environment and in aqueous system constitutes a serious problem to environment due to their resistance to biological degradation processes used today in conventional treatment plants, and even in low concentration may produce serious toxic and other effects to humans and living organism [6-8]. With a growth of population, intensive agriculture and industrialization, a very important role today is played by clean water recovery processes from wastewater for reuse by elimination of antibiotics from terrestrial and aqueous resources.<smiles>CN(C)C1C(O)=C(C(N)=O)C(=O)C2(O)C(O)=C3C(=O)c4c(O)cccc4C(C)(O)C3CC12</smiles>

Fig. 1. Tetracycline chemical structure

Several studies on degradation of tetracycline, using different technologies were conducted: using activated sludge processes [9], $\mathrm{TiO}_{2}$ nanopore arrays electrode [10], $\mathrm{TiO}_{2}$ and $\mathrm{ZnO}$ aqueous suspensions were also used in the photocatalytic oxidation of tetracycline, under simulated solar light [11], photocatalysis of $\mathrm{TC}$ with $\mathrm{C}-\mathrm{N}-\mathrm{S}$ tridoped $\mathrm{TiO}_{2}$ material [12], electron pulse radiolysis [14-17], using Pt plates as anode [14], with $\mathrm{Ti} / \mathrm{RuO}_{2}$ anode [15].

In this study, the electrochemical reactions followed pseudo-first order kinetics. The same type of kinetics was observed in the anodic oxidation of tetracycline at a $\mathrm{Ti} / \mathrm{RuO}_{2}-\mathrm{IrO}_{2}$ anode [16], where the degradation rate increased with current density and decreased with the increasing in the initial antibiotic concentration. Study of the influence of hydroxyl radicals' scavenger showed that anodic oxidation of tetracycline with this anode occurs mainly by direct electron transfer [3].

However, in all previous studies that have used active anodes, no significant levels of mineralization were achieved. In the present study, it is proposed the degradation of tetracycline using a boron-doped diamond (BDD) electrode, a non-active anode.

Recently BDD anodes have received growing attention due to chemical and electrochemical stability, good conductivity and due to his capacity to achieve increased rates of mineralization with very high current efficiencies. In fact, BDD has a long service-life, even when drastic oxidizing conditions are used. This material has a high $\mathrm{O}_{2}$-overpotential and produces a high concentration of hydroxyl radical $(\mathrm{OH})$ on its surface during electrochemical process from water oxidation. $(\cdot \mathrm{OH})$ generated on BDD surface is non-selective, very powerful oxidizing agent, able to react with organics giving dehydrogenated or hydroxylated derivatives till is reached their complete mineralization (total conversion to $\mathrm{CO}_{2}$, water and inorganic anions). Hydroxyl radicals formed from water discharged on the electrode's surface are the main species responsible for the oxidation of the pollutants. 
Due to its upstanding proprieties (a large working potential window of more than 4 volts, particularly useful for water treatment applications; a high chemical stability even in strong acidic or alkaline medium; a non-poisoning of the surface thanks to the possibility of polarity reversal) BDD electrode has multiple applications with great result especially in destruction of organics for wastewater treatment from industrial effluents, organic matter oxidation, COD removal, inorganic matter oxidation [18-20].

Model TC solutions are used and different experimental conditions, namely, initial concentration, initial $\mathrm{pH}$, applied current density, type and concentration of the electrolyte are also tested.

To study the influence of the experimental conditions on the degradation of the antibiotic, assays were performed at experimental conditions that allow kinetic and/or diffusive control, in order to determine medium mass transfer coefficients that help to predict degradation rates at experimental conditions other than those tested.

The evolution of the electrochemical degradation assays with time was followed by UV/Vis spectroscopy, by means of measurements of chemical oxygen demand, total organic carbon and by HPLC. Moreover, for some selected samples the identification and characterization of the analytes, namely degradation products, was achieved by HPLC.

In order to study the influence of the experimental conditions on the mineralization degree of the antibiotic pollutant, the ratio COD/TOC will be determined for the different experimental conditions tested and combustion efficiencies will be calculated.

The influence of the initial concentration and the hydrodynamics inside the electrochemical cell on the rate of electrodegradation and mineralization of TC using a BDD anode will also be assessed.

\section{Experimental}

Tetracycline used in this study was the alkali form, with the chemical formula $\mathrm{C}_{22} \mathrm{H}_{24} \mathrm{~N}_{2} \mathrm{O}_{8} \cdot \mathrm{xH}_{2} \mathrm{O}$, purchased from Sigma Aldrich (purity 99\%) and used without further purification. All reagents ware analytical grade fron Fluka, Panreac or Sigma-Aldrich.

The cyclic voltammetric measurements were performed in a potentiostat/galvanostat VoltaLab PGZ 301. All electrochemical system was described elsewhere [3]. Tetracycline degradation experiments were conducted in batch mode, with recirculation, in an up-flow electrochemical cell, composed by a BDD anode $\left(\right.$ Diachem $\left.^{\circledR}\right)$ and a stainless steel cathode.

Degradation tests were monitored by the following determinations: total organic carbon (TOC) and total nitrogen (TN), measured in a Shimadzu TOC-V CPH analyser combined with a TNM-1 unit; chemical oxygen demand (COD), performed using closed reflux and titrimetric method; total Kjeldahl (TKN) and ammonia nitrogen $\left(\mathrm{N}-\mathrm{NH}_{3}\right)$, determined according to standard procedures, using a Kjeldatherm block-digestion-system and a Vapodest 20s distillation system, both from Gerhardt. UV-Visible absorption spectra were also made, using a Shimatzu UV-1800 spectrophotometer. High performance liquid chromatography (HPLC) was performed using a Merck-Hitachi LaChrom Elite HPLC system equipped with a diode array detector L-2455, a Column Oven L-2300 and a pump L-2130. A RP-18 reversed phase Purospher ${ }^{\circledR}$ STAR (Merk) column $(250 \mathrm{~mm} \times 4 \mathrm{~mm}$, I.D. $5 \mu \mathrm{m})$ was used. Measurements of $\mathrm{pH}$ were carried out with a Mettler-Toledo $\mathrm{pH}$-meter. Conductivity was determined using a conductivity meter Mettler Toledo (SevenEasy S30K). All the solutions for HPLC were prepared with ultrapure water obtained with Milli-Q® equipment [3].

\section{Results and discussion}

Treatment of Tetracycline in aqueous medium was made using electrochemical oxidation, named also electrochemical incineration or cold electrochemical combustion when complete mineralization was achieved. Stainless Steel (SS) and Boron Doped Diamond (BDD) were cathode respectively anode used for this study.

BDD anode has a high oxygen over-potential that permits electrochemical generation in high concentration of radical hydroxyl on the surface of electrode by water oxidation that permits faster mineralization of organics. With a very low activity concerning oxygen formation, oxygen formation potential is $2.3 \mathrm{~V} / \mathrm{SHE}, \mathrm{BDD}$ has a high capacity to produce radical hydroxyl [21, 22]. 
Radical hydroxyl $\cdot \mathrm{OH}$ is a non-selective, very powerful oxidizing agent able to react with organics giving dehydrogenated or hydroxyleted derivatives until complete mineralization is reached (conversion of organics into $\mathrm{CO}_{2}$, water and inorganic ions) [23].

In acidic or neutral medium hydroxyl radical is generated directly at anode surface (Eq. 1).

$$
\begin{aligned}
& \mathrm{H}_{2} \mathrm{O} \rightarrow \mathrm{OH}_{a d s}+H^{+}+e^{-} \\
& \cdot O H_{a d s} \rightarrow \frac{1}{2} O_{2}+H^{+}+e^{-}
\end{aligned}
$$

At $\mathrm{pH} \geq 10$ radical hydroxyl is formed from ion hydroxyl (Eq 3).

$$
\begin{aligned}
& O H^{-} \rightarrow O O H_{a c d}+e^{-} \\
& i_{t}=n F A D_{0}\left(\frac{\partial c_{0}}{\partial x}\right)_{x=0, t}
\end{aligned}
$$

The combustion efficiency of electrochemical treatment applied to Tetracycline solution was estimated by ratio between TOC and COD decay time [18]. Efficiency of combustion $\left({ }^{\eta c}\right)$ calculated is given by Eq 5 .

$$
\eta_{C}=\frac{32}{12}\left(\frac{n}{14 x}\right) \frac{\Delta T O C}{\Delta C O D}
$$

Degradation reaction of TC in aqueous medium after applying electrochemical treatment will be:

$$
\mathrm{C}_{22} \mathrm{H}_{24} \mathrm{O}_{8} \mathrm{~N}_{2}+36 \mathrm{H}_{2} \mathrm{O} \rightarrow 22 \mathrm{CO}_{2}+2 \mathrm{NH}_{4}^{+}+88 \mathrm{H}^{+}+90 \mathrm{e}^{-}
$$

where symbols and units used in above equations, are given in Table1.

Theoretical mathematic model and estimation of COD evolution and of current efficiency in oxidation process in galvanostatic conditions was explained by Comninellis [22]. Variation of limit current intensity in time is expressed as a function of COD.

$$
i_{\text {lim }}(t)=n F k_{m} \operatorname{COD}(t)
$$

When $i_{\text {appliad }}<\boldsymbol{t}_{\text {lim }}$ concentration of contaminant is too high and electrolysis process is controlled by limit current (randament is $100 \%$ and COD linear decrease).

When $i_{\text {appled }}>i_{\text {lim }}$ controlled by phenomena of mass-transport (randament is $<100 \%$ and COD decrease exponential) and seems like unwished secondary reaction.

In order to find out if the process is controlled by diffusion, average current efficiencies (ACE) [6], were calculated according to the following expression:

$$
\mathrm{ACE}=100 \mathrm{~F} \mathrm{~V}\left(\frac{\mathrm{COD}_{\mathrm{t}}-\mathrm{COD}_{0}}{8 \mathrm{I} \Delta \mathrm{t}}\right)
$$

Average mass transfer coefficients based on COD decay, $\mathrm{k}_{\mathrm{mCOD}}$, can be calculated using Eq 9:

$$
\mathrm{COD}_{\mathrm{t}}=\mathrm{COD}_{0} \mathrm{e}^{\frac{\mathrm{Ak_{ \textrm {mcOD } }} \mathrm{V}}{\mathrm{V}}}
$$

where symbols used in above equations are explained in Table 1. 
Table 1. Symbols and measure units used in equations.

\begin{tabular}{|c|c|c|}
\hline Symbol & Name & Units \\
\hline$i_{\lim (t)}$ & $\begin{array}{l}\text { limiting current density at given } \\
\text { time t }\end{array}$ & $A \cdot m^{-2}$ \\
\hline$i_{\text {applied }}$ & applied current density & $A \cdot m^{-2}$ \\
\hline $\mathrm{F}$ & Faraday constant $(\mathrm{F}=96,487)$ & $\mathrm{C}: \mathrm{mol}^{-1}$ \\
\hline I & applied current intensity & $m A$ \\
\hline $\mathrm{t}$ & time of electrochemical treatment & $\mathrm{S}$ \\
\hline$\triangle T O C_{\exp }$ & $\begin{array}{l}\begin{array}{l}\text { variation of experimental } \\
\text { removal }\end{array} \\
\text { TOC }\end{array}$ & $m o l_{c} \cdot m^{-3}$ \\
\hline$\Delta T O C_{\text {theo }}$ & $\begin{array}{l}\text { theoretical TOC decay assuming that } \\
\text { the applied electrical charge is only } \\
\text { consumed in the mineralization } \\
\text { process of Tetracycline }\end{array}$ & $m o l_{c} \cdot m^{-3}$ \\
\hline $\mathrm{k}_{\mathrm{m}}$ & $\begin{array}{l}\text { coefficient of mass transfer in } \\
\text { reactor }\end{array}$ & $\mathrm{m} \cdot \mathrm{s}^{-1}$ \\
\hline $\operatorname{COD}(\mathrm{t})$ & chemical oxygen demand at time $\mathrm{t}$ & $m o l_{O_{2}} \cdot m^{-3}$ \\
\hline $\mathrm{COD}_{\mathrm{o}}(\mathrm{t})$ & initial chemical oxygen demand & $\mathrm{mol}_{\mathrm{O}_{2}} \cdot m^{-3}$ \\
\hline $\mathrm{A}$ & electrode geometric area & $m^{2}$ \\
\hline$V_{R}$ & reservoir volume & $m^{3}$ \\
\hline $\mathrm{V}$ & volume of Tetracycline solution & $m^{3}$ \\
\hline$i_{\lim }^{0}$ & Initial limiting current density & $A \cdot m^{-2}$ \\
\hline$\alpha$ & \multicolumn{2}{|l|}{$\alpha=i_{\text {applied }} / i_{\text {hm }}^{0}$} \\
\hline $\mathrm{n}$ & \multicolumn{2}{|l|}{ number of electrons interchanged } \\
\hline
\end{tabular}

To study of the influence of experimental conditions on the degradation of the antibiotic, assays were performed at experimental conditions that allow kinetic and/or diffusive control, in order to determine medium mass transfer coefficients to predict degradation rates at experimental conditions other than those tested.

The anodic oxidation of tetracycline was performed in an up-flow reactor, operating in batch mode with recirculation, using as anode a boron-doped diamond electrode.

The evolution of the electrochemical degradation assays with time was followed by: cyclic voltammetry, applied for the study of electrochemically generated free radicals. Cyclic voltammograms are obtained by measuring the current at the working electrode during the potential scan of an electrode immersed in an unstirred solution.

The cyclic voltammograms was obtained for sodium sulphate aqueous solutions, $5 \mathrm{~g} \mathrm{~L}^{-1}$, without and with tetracycline, $200 \mathrm{mg} \mathrm{L}^{-1}$, at a scan rate of $10 \mathrm{mV} \mathrm{s}^{-1}$. In the voltammogram of the solution that only contains electrolyte, the presence of an oxidation peaks can be detected, before the oxygen evolution, when tetracycline is also present [3]. As it was explained in detail in a previous study [3], the anodic peak detected is due to the contribution of tetracycline oxidation, showing that tetracycline can also be oxidized before oxygen evolution. In the present case, where the target is the complete mineralization of tetracycline, it was used applied current densities high enough to guarantee the formation of hydroxyl radicals.

At different $[\mathrm{TC}]_{\mathrm{o}}$ tetracycline initial concentration $\left(100\right.$ and $\left.150 \mathrm{mg} \mathrm{L}^{-1}\right)$ were performed four different assays coresponding to different recirculation flow rate: FR1 $=37 \mathrm{~L} \mathrm{~h}^{-1}$; FR2 $=75 \mathrm{~L} \mathrm{~h}^{-1}$; FR3 $=100 \mathrm{~L} \mathrm{~h}^{-1}$ at constant current density, $300 \mathrm{~A} \mathrm{~m}^{-2}$, using as electrolyte a sodium sulfate aqueous solution, $5 \mathrm{~g} \mathrm{~L}^{-1}$. The duration of the experiments with tetracycline initial concentration of $100 \mathrm{mg} \mathrm{L}^{-1}$ was $4 \mathrm{~h}$. When initial concentration was $150 \mathrm{mg} \mathrm{L}^{-1}$ the duration of the tests was 
extended to $6 \mathrm{~h}$, to ensure that almost complete degradation of organic matter was achieved. A summary of the main results obtained in the electrodegradation assays at flow rate $100 \mathrm{~L} \mathrm{~h}^{-1}$, is presented in Table 2. All these results refer to $4 \mathrm{~h}$ assay, in order to make comparison easier.

Table 2. Results obtained after $4 \mathrm{~h}$ of electrodegradation of TC with different initial tetracycline concentrations on BDD at a recirculation flow rate FR3 $=100 \mathrm{~L} \mathrm{~h}^{-1}$

\begin{tabular}{|c|c|c|c|c|c|c|c|c|}
\hline $\begin{array}{l}{[\mathrm{TC}]_{0}^{*} /} \\
\mathrm{mg} \mathrm{L}^{-1}\end{array}$ & COD & TOC & $\begin{array}{l}\text { ACE / } \\
\%\end{array}$ & $\begin{array}{l}\mathbf{k}_{\mathrm{mCOD}} / \\
10^{-5} \mathrm{~m} \mathrm{~s}^{-1}\end{array}$ & $\begin{array}{l}\mathbf{N}-\mathbf{N H}_{3} / \\
\mathrm{mg} \mathrm{L}^{-1} \\
\text { (FINAL) }\end{array}$ & TKN & TN & $\begin{array}{l}\operatorname{Abs}_{(4 \mathrm{~h})} \\
\text { Removal / \% } \\
(360 \mathrm{~nm})\end{array}$ \\
\hline 100 & 86 & 83 & 1.6 & 0 & 3.7 & 5.2 & 5.28 & 99.8 \\
\hline 150 & 93 & 87 & 2.5 & 0 & 5.1 & 5.6 & 5.70 & 100 \\
\hline
\end{tabular}

For initial concentrations 100 and $150 \mathrm{mg} \mathrm{L}^{-1}, \mathrm{COD}$ and TOC relative decays increase with flow rate and, for similar recirculation flow rate the removal rate of the organic load increases with initial concentration. These results corresponding to all three recirculation rate $\left(\mathrm{FR} 1=37 \mathrm{~L} \mathrm{~h}^{-1} ; \mathrm{FR} 2=75\right.$ $\mathrm{L} \mathrm{h}^{-1}$; FR3 $=100 \mathrm{~L} \mathrm{~h}^{-1}$ ) detailed explained in a previous paper [3] where the influence on the degradation rate of tetracycline initial concentration and recirculation flow rate were investigated, assuming that electrodegradation process is under diffusion control. In order to find out if the process is controlled by diffusion, average current efficiencies (ACE) from Table 2, were calculated according to the Eq. 8, obtaining very low values which comes in support of diffusion control.

The elimination of organic matter fallows a pseudo-first order kinetic, which can be observed by exponential decay of the relative removal of COD and TOC with time. At the highest degradation rate tested, $100 \mathrm{~L} \mathrm{~h}^{-1}$, with an initial tetracycline concentration of $150 \mathrm{mg} \mathrm{L}^{-1}$, after $4 \mathrm{~h}$ assay, the removals of COD, TOC and absorbance (measured at 276.5 and $360.0 \mathrm{~nm}$ ) were 93, 87, 99 and $100 \%$, respectively.

The variation of tetracycline concentration with time at different current density values $(50,200$, 400, $600 \mathrm{mAcm}^{-2}$ ) applied for electrochemical degradation of $100 \mathrm{mg} \mathrm{L}^{-1} \mathrm{TC}$, are depicted in Fig 2 . The concentration of tetracycline decreases in time. In HPLC analyses the results obtained for this assay (data not shown) indicate that at high current density, the main compound and the metabolites that may occure, are fast degradated at BDD surface. The variation of tetracycline concentration with time in case of degradation of TC solutions with different initial $\mathrm{pH}$, was depicted in Fig 3. The behavior of this TC solutions with different $\mathrm{pH}$ are the subject of a future new publication.

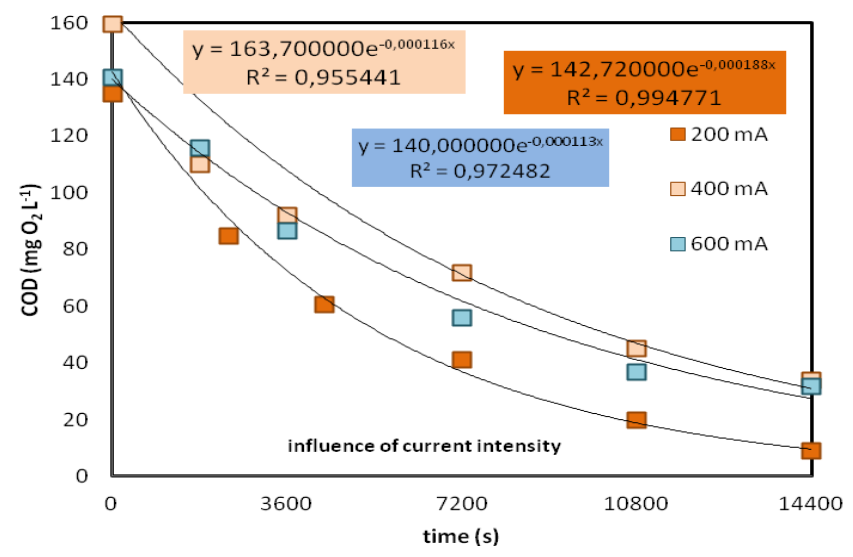

Fig. 2. Variation of COD for TC electrochemical degradation $\left([\mathrm{TC}]_{0}=100 \mathrm{mg} \mathrm{L}^{-1}\right)$ at different current intensity 


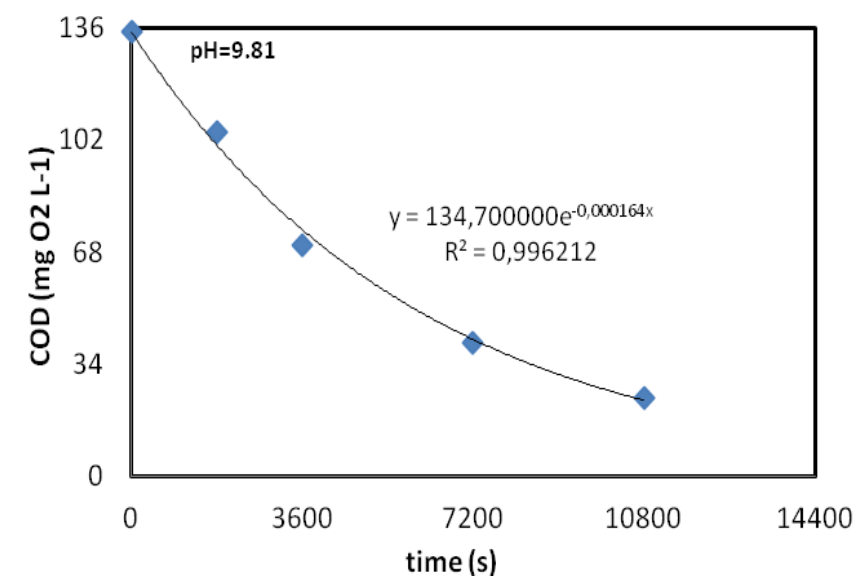

Fig. 3. Variation of COD in time for tetracycline degradation at $\mathrm{pH}(9.81)$

It was possible to determinate the mass transfer coefficients, $\mathrm{k}_{\mathrm{m}}$, for the different flow rates (Eq. 13), by calculating Re, Sc and Sh (Eq.10 to 13).

$$
\begin{aligned}
& \mathrm{Re}=\frac{\rho \mathrm{vL}}{\mu} \\
& \mathrm{Sc}=\frac{\mu}{\rho \mathrm{D}} \\
& \mathrm{Sh}=0.646 \mathrm{Sc}^{1 / 3} \mathrm{Re}^{1 / 2} \\
& \mathrm{k}_{\mathrm{m}}=\frac{\mathrm{Sh} \mathrm{D}}{\mathrm{L}}
\end{aligned}
$$

where $\rho, \mu$ and $v$ are, respectively, density and viscosity of the solution and the linear rate of the solution inside the electrochemical cell. $\mathrm{L}$ is the characteristic dimension of the cell, here represented by the hydraulic diameter, defined as the free area for flow over the wet perimeter. The $\mathrm{k}_{\mathrm{m}}$ values thus obtained are: FR1 - $5.07 \times 10^{-6} \mathrm{~m} \mathrm{~s}^{-1}$; FR2 - 7.21 x $10^{-6} \mathrm{~m} \mathrm{~s}^{-1}$; FR3 - $8.33 \times 10^{-6}$ $\mathrm{m} \mathrm{s}^{-1}$. Using these $\mathrm{k}_{\mathrm{m}}$ and $\mathrm{D}$ values, the apparent width of the diffusion layer for the different FRs can be calculated and are 117, 82 and $71 \mu \mathrm{m}$, respectively, for FR1, FR2 and FR3.

It was observed that values for $\mathrm{k}_{\mathrm{mCOD}}$ are higher than for $\mathrm{k}_{\mathrm{m}}$, particularly for the assays run at higher tetracycline initial concentration. As a conclusion the diffusion layer is larger for low flow rate and low initial concentration in tetracycline, and the organics are not oxidized by hydroxyl radicals because they exist mainly near the electrode surface and organic molecules are spread in a larger area. At higher TC initial concentration and low flow rate, the concentration in organics is higher and oxidation by hydroxyl radicals can be more efficient. When flow rate increases, the width of the diffusion layer decreases and the attack by hydroxyl radicals to the organic molecules becomes much easier, leading to increases of rates of oxidation higher than those of mass transfer [3].

\section{CONCLUSIONS}

The removal to below the limit of detection of pharmaceuticals (TC) from ground and surface waters destined for drinking water production is obviously imperative. Since conventional drinking water treatments have failed to remove these compounds, it is imperative to develop new technologies suitable for water production plants. Electrodegradation with BDD electrode are promising technologies for electrochemical degradation of TC the high removals of COD show that the metabolites formed during the process are also oxidized, with a high degree of mineralization, since TOC removals are also very high. Average mass transfer coefficients increase with 
recirculation flow rate, probably due to a decrease in the width of the diffusion layer that favours the mass transfer process. During the electrodegradation assay the organic nitrogen is mainly converted to ammonium, nitrate and nitrite.

Due to its upstanding properties BDD electrode has multiple applications with a high mineralization degree of TC. In all experimental systems with different electrochemical cells when an up-flow reactor, operating in batch mode with recirculation was used-for degradation of TC solution, is achieved a high degree of removal of pollutants through their complete mineralization of up to $100 \%$. Thus BDD electrode is a great electrode material for multiple applications with excellent results especially in destruction of organics for wastewater treatment from industrial effluents, organic matter oxidation, COD removal, inorganic matter oxidation.

\section{Acknowledgments}

This paper was supported by the project "Development and support of multidisciplinary postdoctoral programmes in major technical areas of national strategy of Research - Development Innovation" 4D-POSTDOC, contract no. POSDRU/89/1.5/S/52603, project co-funded by the European Social Fund through Sectoral Operational Programme Human Resources Development 2007-2013. The authors also want to thank Fundação para a Ciência e a Tecnologia, Portugal.

\section{References}

[1] K. Kümmerer, Antibiotics in the aquatic environment-A review-Part I, Chemosphere 75 (2009) 417-434.

[2] S.A. Sassman, L.S. Lee, Sorption of three tetracyclines by several soils: Assessing the role of $\mathrm{pH}$ and cation exchange, Environmental Science and Technology 39 (2005) 7452-7459.

[3] C. I. Brinzila, M.J. Pacheco, L. Ciríaco, R.C. Ciobanu, A. Lopes, Electrodegradation of tetracycline on BDD anode, Chemical Engineering Journal 209 (2012) 54-61.

[4] G. Gu, K.G. Karthikeyan, Interaction of tetracycline with aluminium and iron hydrous oxides, Environmental Science and Technology 39 (2005) 2660-2667.

[5] H. Yamamoto, Y. Nakamura, S. Moriguchi, Y. Nakamura, Y. Honda, I Tamura, Y. Hirata, A. Hayashi, J. Sekizawa, Persistence and partitioning of eight selected pharmaceuticals in the aquatic environment: Laboratory photolysis, biodegadation, and sorption experiments, Water Research 43 (2009) 351-362.

[6] S. Kim, P. Eichhorn, J.N. Jensen, A.S. Weber, D.S. Aga, Removal of antibiotics in wastewater: effect of hydraulic and solid retention times on the fate of Tetracycline in the activated sludge process, Environmental Science and Technology 39 (2005) 5816-5823.

[7] A. Boxall, D. Kolpin, B. Holling-Sorensen, J. Tolls, Are veterinary medicines causing environmental risks? Environ. Sci. Techol. 37 (2003) 287A-294A.

[8] R. Hirsch, T. Ternes, K. Haberer, K.L. Kratz, Occurrence of antibiotics in the aquatic environment, Sci. Total Environ. 225 (1999) 109-118.

[9] S. Kim, P. Eichhorn, J.N. Jensen, A.S. Tweber, D.S. Aga, Removal of antibiotics in wastewater: Effect of hydraulic and solid retention times on the fate of tetracycline in the activated sludge process, Environ. Sci. Technol. 39 (2005) 5816-5823.

[10] Y. Liu, X. Gan, B. Zhou, B. Xiong, J. Li, C. Dong, J. Bai, W. Cai, Photoelectrocatalytic degradation of tetracycline by highly effective $\mathrm{TiO}_{2}$ nanopore arrays electrode, J. Hazard. Mater. 171 (2009) 678-683.

[11] R.A. Palominos, M.A. Mondaca, A. Giraldo, G. Peñuela, M. Pérez-Moya, H.D. Mansilla, Photocatalytic oxidation of the antibiotic tetracycline on $\mathrm{TiO}_{2}$ and $\mathrm{ZnO}$ suspensions, Catal. Today 144 (2009) 100-105.

[12] P. Wang, P-S. Yap, T.T. Lim, C-N-S tridoped $\mathrm{TiO}_{2}$ for photocatalytic degradation of tetracycline under visible-light irradiation, Appl. Catal. A: Gen. 399 (2011) 252-261. 
[13] J. Jeong, W. Song, W.J. Cooper, J. Jung, J. Greaves, Degradation of tetracycline antibiotics: Mechanisms and kinetic studies for advanced oxidation/reduction processes, Chemosphere 78 (2010) 533-540.

[14] M.D. Vendenyapina, Y.N. Eremicheva, V.A. Pavlov, A.A. Vendenyapin, Electrochemical degradation of tetracycline, Russ. J. Appl. Chem. 8 (2008) 800-802.

[15] A. Rossi, V.A. Alves, L.A. Da Silva, M.A. Oliveira, D.O.S. Assis, F.A. Santos, R.R.S. De Miranda, Electrooxidation and inhibition of the antibacterial activity of oxytetracycline hydrochloride using $\mathrm{RuO}_{2}$ electrode, J. Appl. Electrochem. 39 (2009) 329-337.

[16] H. Zhang, F. Liu, X.G. Wu, J.H. Zhang, D.B. Zhang, Degradation of tetracycline in aqueous medium by electrochemical method, Asia-Pac. J. Chem. Eng. 4 (2009) 568-573.

[17] M. Miyata, I. Ihara, G. Yoshid, K. Toyod K. Umetsu, Electrochemical oxidation of tetracycline antibiotics using a $\mathrm{Ti} / \mathrm{IrO}_{2}$ anode for wastewater treatment of animal husbandry, Wat. Sci. Technol. 63 (2011) 456-461.

[18] L. Ciríaco, C. Anjo, J. Correia, M.J. Pacheco, A. Lopes, Electrochemical degradation of Ibuprofen on Ti/Pt/PbO 2 and $\mathrm{Si} / \mathrm{BDD}$ electrodes, Electrochim. Acta, 54 (2009) 1464-1472.

[19] M. Panizza, G. Cerisola, Application of diamond electrodes to electrochemical processes, Electrochim. Acta 51 (2005) 191.

[20] I. Sirés, E. Brillas, Remediation of water pollution caused by pharmaceutical residues based on electrochemical separation and degradation technologies: A review, Environment International 40 (2012) 212-229.

[21] Ch. Comninellis, C. Pulgarin, Anodic oxidation of phenol for wastewater treatment, J. Appl. Electrochem. 21 (1991) 703-708.

[22] Ch. Comninellis, C. Pulharin, Electrochemical oxidation of phenol for wastewater treatment using $\mathrm{SnO}_{2}$ anodes, J.Appl. Electrochem. 23 (1993) 108-112.

[23] Ch. Comninellis, Application of synthetic BDD electrodes in electrooxidation, in Diamond Electrochemistry, Elsevier, Amsterdam (2005) 449-476. 